\title{
Avaliação in vitro do potencial antimicrobiano de Streptomyces sp G-27 contra microrganismos de interesse clínico
}

\author{
Hanna Katarina Lopes Ferreira*, Suellen Emilliany Feitosa Machado, \\ Raphael Carlos Ferrer de Santana, Luiz Eduardo Felix de \\ Albuquerque, Isllan D'Eric Gonçalves da Silva, Glêzia Renata da \\ Silva-Lacerda, Janete Magali de Araújo, Gláucia Manoella de Souza \\ Lima
}

Universidade Federal de Pernambuco. Campus Recife. Av. Professor Moraes Rego, 1235. Cidade Universitária. Recife-PE. Brasil. (CEP 50670-901). *E-mail: hannakatarina0@gmail.com.

Resumo. Actinobactérias ou actinomicetos são bactérias filamentosas gram-positivas, normalmente isoladas do solo e que constituem um dos maiores filos bacterianos. Possuem grande potencial biotecnológico, pois são reconhecidamente produtoras de enzimas, pigmentos, substâncias com ações antibióticas, antitumoral, antihelmíntica e antifúngica, entre outros. Apesar da resistência aos antimicrobianos ser considerada um fenômeno natural de adaptação dos microrganismos às drogas, o surgimento de cepas resistentes conduz à ineficácia da terapia medicamentosa. A resistência antimicrobiana é encarada como desafio e, nesse contexto, a exploração dos produtos naturais apresenta-se como alternativa para a descoberta de novos fármacos antimicrobianos e, consequentemente, para o combate a esse tipo de resistência. Assim, este trabalho teve como objetivo investigar o potencial antimicrobiano da cepa Streptomyces sp G-27 frente a microrganismos de interesse clínico. O microrganismo foi cultivado em ágar ISP-2, a $37^{\circ} \mathrm{C}$, durante $120 \mathrm{~h}$. Os testes de atividade antimicrobiana foram realizados em bloco de gelose, medindo $8 \times 8 \mathrm{~mm}$ de diâmetro, frente à bactérias grampositivas, gram-negativas e levedura. Para estes microrganismos, foram preparadas suspensões com densidade de 0,5 da Escala de McFarland, que foram semeadas em placas contendo Ágar Mueller Hinton para bactérias e Ágar Sabouraud para a levedura. Os blocos de gelose foram colocados sobre as placas inoculadas, as quais foram incubadas a $37{ }^{\circ} \mathrm{C}$ por $24 \mathrm{~h}$ para bactérias e a $30{ }^{\circ} \mathrm{C}$ por $48 \mathrm{~h}$ para a levedura. $\mathrm{O}$ ensaio foi realizado em triplicata. Após o período de cultivo, o diâmetro dos halos foi medido e os resultados foram obtidos pela média aritmética das triplicatas. Streptomyces sp G-27 apresentou atividade contra Staphylococcus aureus, Enterococcus faecium, Escherichia coli, Klebisiella pneumoniae e Candida albicans. Observou-se que a actinobactéria testada possui atividade antimicrobiana contra cinco dos seis microrganismos teste utilizados, revelando perspectivas sobre o potencial biotecnológico de tal microrganismo, que foi isolado da Caatinga, uma região de microbiota pouco explorada.
Recebido:

11/08/2016

Aceito:

27/12/2016

Publicado:

31/12/2016

Acesso Aberto

Artigo completo

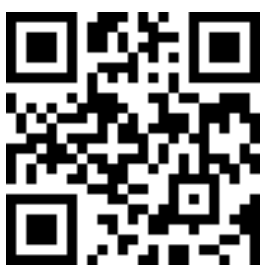

ORCID

(1) 0000-0002-3252-5421

Hanna Katarina Lopes Ferreira

(1) 0000-0001-5608-1768

Suellen Emilliany

Feitosa Machado

(D) 0000-0003-2533-6195

Raphael Carlos Ferrer de Santana

(b) 0000-0002-0220-2197

Luiz Eduardo Felix de

Albuquerque 
Palavras-chave: Streptomyces sp; Metabólitos secundários; Atividade antimicrobiana.

Abstract. Actinobacteria or Actinomycetes are filamentous grampositive bacteria, usually isolated from soil and constitute one of the major bacterial phyla. They have great biotechnological potential, because they are known as producers of enzymes, pigments, substances with antibiotic action, antitumor, anthelmintic and antifungal producers, among others. Despite the resistance to antimicrobials is considered a natural phenomenon of adaptation of microorganisms to drugs, the emergence of resistant strains leads to ineffectiveness of drug therapy. Antimicrobial resistance is seen as a challenge and, in this context, the use of natural products appear as an alternative to the discovery of new antimicrobial drugs and, consequently, to combat this type of resistance. This work aimed to investigate the antimicrobial potential of the strain Streptomyces sp G-27 against interest clinical microorganisms. The microorganism was grown in ISP-2 agar at $37{ }^{\circ} \mathrm{C}$ for $120 \mathrm{~h}$. The antimicrobial activity tests were performed on agar block, measuring $8 \times 8 \mathrm{~mm}$ of diameter against gram-positive, Gram-negative bacteria and yeast. For these microorganisms, suspensions were prepared with a density of 0.5 McFarland Scale, which were seeded in plates containing Mueller Hinton agar for bacteria and Sabouraud agar for yeast. The agar blocks were placed on the seeded plates, which were incubated at $37^{\circ} \mathrm{C}$ for $24 \mathrm{~h}$ for bacteria and at $30^{\circ} \mathrm{C}$ for $48 \mathrm{~h}$ for yeast. The assay was performed in triplicate. After the cultivation, the diameter of the halos was measured and the results were obtained by the arithmetic mean of triplicates. Streptomyces sp G-27 showed activity against Staphylococcus aureus, Enterococcus faecium, Escherichia coli, Klebisiella pneumoniae and Candida albicans. It was observed that the tested actinobacteria has antimicrobial activity against five of the six microorganisms test used, revealing perspectives on the biotechnological potential of the microorganism, which was isolated from Caatinga a region with microbiota bit explored.

Keywords: Streptomyces sp; Secondary metabolites; Antimicrobial activity.

\section{Introdução}

Actinobactérias são bactérias grampositivas que constituem um dos maiores filos bacterianos. São seres ubíquos, sendo encontrados em ambientes aquáticos e terrestres. Apresentam organização micelial, possuem um extenso metabolismo secundário e produzem cerca de dois terços de todos os antimicrobianos derivados da natureza, além de substâncias com ações antitumorais, anti-helmínticas e antifúngicas. Assim, essas bactérias possuem grande importância para a biotecnologia, medicina e agricultura. Além disso, algumas espécies vivem em
(1) 0000-0002-0841-4051 Isllan D’Eric Gonçalves da Silva

0000-0001-6706-5667 Glêzia Renata da SilvaLacerda

(ㄷ) 0000-0001-8878-4820 Janete Magali de Araújo

(1) 0000-0002-1941-8912 Gláucia Manoella de Souza Lima 
estreptomicina, cloranfenicol, eritromicina, canamicina, novobiocina, vancomicina, nistatina e anfotericina B (Silva-Lacerda et al., 2016). Neste contexto, Barka et al. (2016) acrescentam que o gênero Streptomyces é extremamente valioso do ponto de vista biotecnológico, pois engloba produtores de enzimas de aplicação industrial e antibióticos comerciais, como a estreptomicina. Além disso, é o gênero mais conhecido dentre as actinobactérias, incluindo mais de 3.000 espécies identificadas.

O marco da quimioterapia microbiana ocorreu com o descobrimento da penicilina, substância produzida por um fungo do gênero Penicillium, cuja capacidade de inibir o crescimento da bactéria Staphylococcus aureus foi descoberta acidentalmente por Alexander Fleming, no ano de 1928. Porém, seu emprego em larga escala só teve início na década de 1940. O grande impacto do uso penicilina motivou sua produção industrial, sendo este 0 primeiro medicamento produzido em grande escala. Assim, iniciou-se a exploração dos microrganismos como fonte de substâncias biologicamente ativas, principalmente na busca de novas substâncias com atividade antibiótica (Takahashi e Lucas, 2008).

Porém, em virtude de fatores diversos, dentre eles o uso indiscriminado de agentes antimicrobianos, observou-se o surgimento do fenômeno de resistência dos microrganismos a tais substâncias. A resistência microbiana é um dos obstáculos mais significativos para a saúde pública e está ameaçando desfazer décadas de avanços em sua capacidade para tratar a doença através dos produtos naturais. Os efeitos colaterais e de resistência que os microrganismos patogênicos construíram contra os antibióticos provocam falha no tratamento principal. Uma maneira de combater o problema da resistência microbiana é o desenvolvimento de novos agentes antibacterianos naturais para substituição dos ineficazes (Senthil-Rajan et al., 2013).

Desta forma, estudos utilizando microrganismos oriundos do meio ambiente como produtores de metabólitos secundários são cada vez mais comuns.
Sendo a Caatinga um bioma singular devido à grande variedade de paisagens, relativa riqueza biológica e endemismo (Silva-Lacerda et al., 2016), torna-se interessante explorar tal região como fonte de substâncias de interesse biotecnológico. Marschner et al. (2004) afirmam que os solos têm comunidades microbianas distintas devido a diversos fatores, os quais incluem características físico-químicas do solo (nutrientes, teor de matéria orgânica e $\mathrm{pH}$, dentre outros) e fatores ambientais (como clima e vegetação), o que pode estimular a produção de diferentes metabólitos secundários pelos microrganismos. Esta produção ocorre em resposta às adaptações para uma função específica na natureza.

Assim, considerando o aumento da resistência dos microrganismos aos antimicrobianos existentes no mercado, observa-se uma necessidade de encontrar outros agentes com potencial atividade antimicrobiana. Neste contexto, a realização de pesquisas buscando novos agentes aparece como uma alternativa para este fim. Portanto, sabendo que o bioma da Caatinga possui uma microbiota variada por apresentar características únicas, torna-se interessante estudar a diversidade microbiológica desse ambiente e, consequentemente, seu potencial biotecnológico.

Este trabalho teve como objetivo investigar o potencial antimicrobiano da cepa Streptomyces sp G-27 frente a microrganismos de interesse clínico.

\section{Metodologia}

\section{Microrganismo}

A actinobactéria Streptomyces sp G-27 foi previamente isolada de uma amostra de solo oriundo da Região Semiárida da Caatinga, mais especificamente da rizosfera da planta catingueira (Caesalpinia pyramidalis Tul.) (Corrêa et al., 2014).

Streptomyces sp G-27 encontra-se armazenado em óleo mineral, na Coleção de Microrganismos UFPEDA, do Departamento de Antibióticos, da Universidade Federal de Pernambuco. 


\section{Reativação}

O microrganismo foi reativado em meio ISP-2 líquido, a $160 \mathrm{rpm}$, a $37{ }^{\circ} \mathrm{C}$, durante 5 dias. Após esse período, uma alíquota deste meio foi retirada com o auxílio de uma alça estéril e semeada em meio ISP-2, procedendo-se a incubação por cinco dias, a $37^{\circ} \mathrm{C}$.

\section{Determinação da atividade antimicrobiana}

Ensaio primário. Para avaliação da atividade antimicrobiana dos isolados, foi realizada uma seleção primária seguindo a metodologia proposta por Ichikawa et al. (1971), conhecida como "Método do Bloco de Gelose” ou “Teste de difusão em Ágar”. Neste processo, o composto bioativo difunde-se no ágar.

Inicialmente, elaborou-se uma suspensão de esporos de Streptomyces sp G-27 em solução salina a 0,9\% estéril. Esta suspensão foi submetida à agitação em vórtex e $0,1 \mathrm{~mL}$ foi espalhada com o auxílio de uma alça de Drigalsky em placa de Petri contendo o meio ISP-2. A placa foi incubada por cinco dias, a $37^{\circ} \mathrm{C}$, a fim de se obter um crescimento em forma de tapete.

Decorrido este tempo, verificando o crescimento satisfatório, foram retirados blocos circulares medindo $8 \mathrm{~mm}$ de diâmetro, utilizando um perfurador de colônias previamente esterilizado. Estes blocos foram colocados sob os microrganismos testes anteriormente plaqueados, os quais são relatados no tópico a seguir.

Microrganismos teste. Para os testes de atividade antimicrobiana, foram utilizadas duas bactérias gram-positivas, três gram-negativas e uma levedura. Estes microrganismos foram cedidos pela Coleção de Microrganismos-UFPEDA, do Departamento de Antibióticos, da Universidade Federal de Pernambuco, e são descritos na Tabela 1.

Tabela 1. Microrganismos utilizados na investigação do potencial antimicrobiano de Streptomyces sp G-27.

\begin{tabular}{ll}
\hline & Microrganismos-teste \\
\hline Bactérias gram-positivas & Staphylococcus aureus (UFPEDA-02) \\
& Enterococcus faecium (UFPEDA-138) \\
Bactérias gram-negativas & Escherichia coli (UFPEDA-224) \\
& Pseudomonas aeruginosa (UFPEDA-396) \\
& Klebisiella pneumoniae (UFPEDA-416) \\
Levedura & Candida albicans (UFPEDA-1007) \\
\hline
\end{tabular}

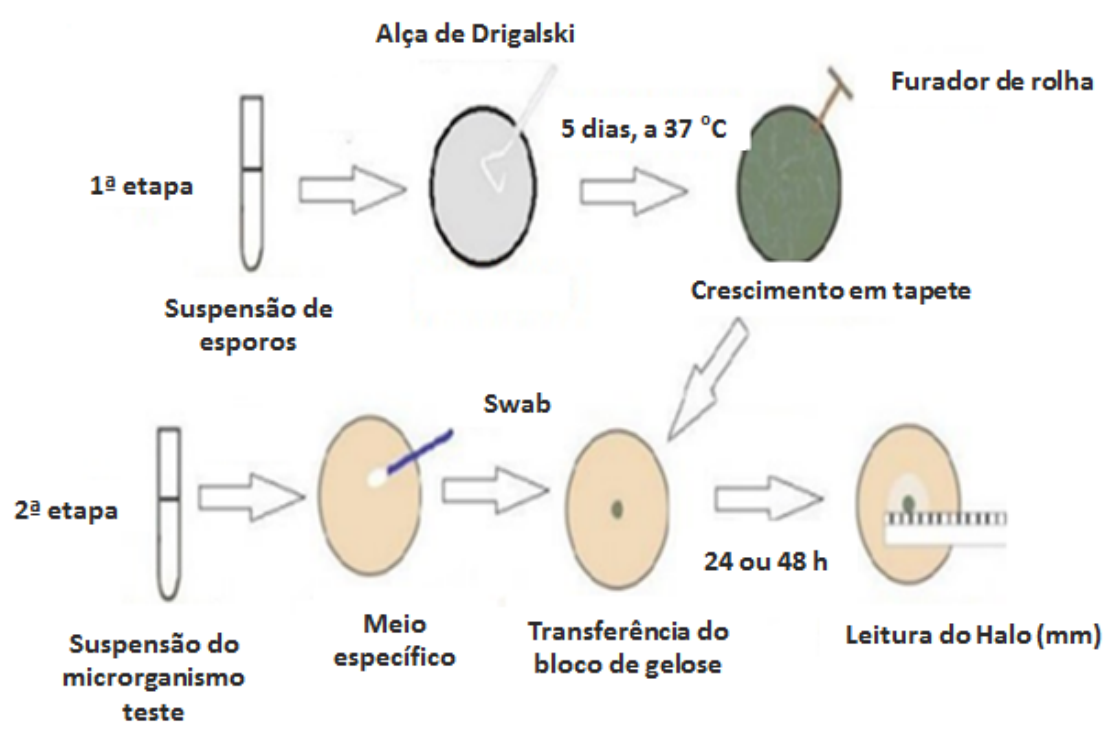

Figura 1. Esquema da realização do método “bloco de gelose”. (Fonte: Adaptado de Bernardo, 2012). 
Para a atividade antimicrobiana, foram preparadas suspensões das bactérias e da levedura com densidade de 0,5 da Escala de McFarland. As suspensões foram semeadas em placas contendo Ágar Mueller Hinton para bactérias e Ágar Sabouraud para a levedura. O teste foi realizado em triplicata.

As placas foram incubadas a $37{ }^{\circ} \mathrm{C}$ por $24 \mathrm{~h}$ para bactérias e a $30^{\circ} \mathrm{C}$ por $24-48$ $\mathrm{h}$ para a levedura. Após o período de cultivo, o diâmetro dos halos foi medido e os resultados foram obtidos pela média aritmética das triplicatas. A metodologia para realização dos testes aqui descritos encontra-se esquematizada na Figura 1.

\section{Resultados e discussão}

O microrganismo Streptomyces sp G-27 apresentou atividade antimicrobiana contra cinco dos seis microrganismos testados, conforme descrito na Tabela 2. Como é possível observar, os maiores halos de inibição foram formados contra Enterococcus faecium e Staphylococcus aureus. Nas condições testadas, não houve inibição do crescimento de Pseudomonas aeruginosa.

Tabela 2. Média aritmética dos halos de inibição $(\mathrm{mm})$ de Streptomyces sp G-27 frente a microrganismos de interesse clínico.

\begin{tabular}{lc}
\hline Microorganismo-teste & Halos (mm) \\
\hline Staphylococcus aureus & 29,5 \\
Enterococcus faecium & 31,0 \\
Escherichia coli & 14,0 \\
Pseudomonas aeruginosa & - \\
Klebisiella pneumoniae & 10,0 \\
Candida albicans & 16,0 \\
\hline
\end{tabular}

(-): não houve halo de inibição

O ensaio de bloco de gelose é um método físico no qual um microrganismo teste é desafiado contra uma substância biologicamente ativa em meio de cultura sólido e relaciona o tamanho da zona de inibição de crescimento do microrganismo desafiado com a concentração da substância testada.

Este ensaio permitiu então, que o metabólito secundário produzido pela actinobactéria Streptomyces sp G-27 se difundisse no meio de cultura, impedindo o crescimento da grande maioria dos microrganismos-teste, mostrando, assim, ser uma metodologia satisfatória para este fim.

De acordo com Mendes (2010), actinobactérias são abundantemente conhecidas devido ao seu potencial na produção de moléculas bioativas, consequência de seu metabolismo secundário, o que pode justificar os resultados obtidos neste trabalho.
Zhao et al. (2009) também executaram um teste de difusão em ágar de actinobactérias isoladas de sedimentos marinhos, constatando que algumas cepas investigadas demostraram vasto espectro ação: alguns isolados apresentaram atividade fungicida, à medida que outros apresentaram atividade contra Pseudomonas aeruginosa, Staphylococcus aureus e Bacillus subtilis, com halos de até $22 \mathrm{~mm}, \quad 30 \mathrm{~mm}, 25 \mathrm{~mm}$ e $26 \mathrm{~mm}$, respectivamente. Assim, os resultados obtidos por Zhao et al. (2009) estão em concordância com os resultados do presente trabalho.

Ao analisar o tamanho dos halos de inibição apresentados na Tabela 2, pode-se notar que a atividade antimicrobiana contra bactérias gram-positivas (Enterococcus faecium e Staphylococcus aureus) foi maior do que para as gram-negativas (Escherichia coli e Klebisiella pneumoniae) e para a levedura (Candida albicans). Segundo Madigan (2010), o menor percentual de 
atividade antimicrobiana frente a gramnegativos é consequente da natureza complexa de sua parede celular, a qual possui uma membrana externa ao seu redor, o que confere maior resistência à ação de antibióticos, os quais não são capazes de transpassar tal barreira lipídica.

O aumento do número de casos de resistência a antibióticos por microrganismos da prática clínica multirresistentes e a falta de opções terapêuticas a curto e médio prazo para tratamento das infecções causadas por essas por eles reforçam necessidade de se encontrar novas alternativas terapêuticas para tratar infecções. De acordo com Boucher et al. (2009), microrganismos como Enterococcus faecium, Staphylococcus aureus, Klebsiella pneumoniae, Acinetobacter baumanni, Pseudomonas aeruginosa e Enterobacter spp. são as bactérias mais prevalentes causadoras da maioria das infecções hospitalares nos EUA e efetivamente escapam da ação dos antibacterianos.

As doenças infecciosas são a segunda maior causa de mortalidade no mundo. O número total de novos agentes antimicrobianos aprovados pela FDA (Food and Drug Administration) sofreu um decréscimo. Assim, a busca por novos agentes que atuem por mecanismos de ação diferentes dos fármacos em uso precisou ser intensificada. A resistência microbiana, especialmente em ambientes hospitalares, encontra-se com taxas elevadas e, com isso, surgiu uma necessidade imediata pela busca de novos antibióticos (Guimarães et al., 2010). Desta forma, este estudo qualitativo realizado com diversos microrganismos de interesse clínico pode ser considerado promissor, pois indica que Streptomyces sp G-27 é produtor de um agente antimicrobiano, o qual precisa ser e identificado em estudos subsequentes.

Os resultados obtidos confirmam que as bactérias do gênero Streptomyces sp são capazes de inibir o crescimento de outros microrganismos. Assim, actinobactérias aparecem como uma fonte útil e poderosa para a produção de metabólitos de interesse biotecnológico, especialmente para a obtenção de novos antibióticos.

\section{Conclusão}

A pesquisa por novos antibióticos continua objetivando combater bactérias e fungos resistentes, melhorar as propriedades farmacológicas, combater tumores e parasitas. Desta forma, os halos de inibição do crescimento dos microrganismos de interesse clínico demostraram que a actinobactéria Streptomyces sp G-27 aparece como possível fonte de compostos naturais bioativos, apresentando-se como uma bactéria de considerável potencial biotecnológico. Ademais, este trabalho enaltece as pesquisas realizadas com microrganismos isolados de regiões cuja microbiota ainda é pouco explorada, a Caatinga. Outros estudos estão em andamento visando aprimorar as condições de produção do metabólito secundário, bem como para extrair e purificá-lo.

\section{Declaração de conflitos de interesse}

Os autores declaram não haver conflitos de interesses.

\section{Referências}

Barka, E. A.; Vatsa, P.; Sanchez, L.; GaveauVaillant, N.; Jacquard, C.; Klenk, H. P.; Clément, C.; Ouhdouch, Y.; Wezel, G. P. V. Taxonomy, physiology, and natural products of Actinobacteria. Microbiol. Mol. Biol. Rev., $\begin{array}{llll}\text { v. } 80, & \text { n. } 1, \quad \text { p. 1-43, } 2016 .\end{array}$ http://dx.doi.org/10.1128/MMBR.00019-15

Bernardo, G. R. B. Atividade antifúngica de actinobactérias da rizosfera de Terminalia fagifolia (Bioma Caatinga) ativas contra Candida spp. Recife: Universidade Federal de Pernambuco, 2012. (Trabalho de Conclusão de Curso).

Boucher, H. W.; Talbot, G. H.; Bradley, J. S.; Edwards, J. E.; Gilbert, D.; Rice, L. B.; Scheld, M.; Spellberg, B.; Bartlett, J. Bad bugs, no drugs: no ESKAPE! An update from the Infectious Diseases Society of America. Clin. Infect. Dis., v. 48, n. 1, p. 1-12, 2009. http://dx.doi.org/10.1086/595011

Corrêa, G. G. Potencial biotecnológico de actinobactérias da rizosfera de Caesalpinia pyramidalis Tul. do Bioma Caatinga. Recife: Universidade Federal de Pernambuco, 2014. (Dissertação de Mestrado). 
Guimarães, D. O.; Momesso, L. S.; Pupo, M. T. Antibióticos: importância terapêutica e perspectivas para a descoberta e desenvolvimento de novos agentes. Quím. Nova, v. 33, n. 3, p. 667-679, 2010. http://dx.doi.org/10.1590/S010040422010000300035

Ichikawa, T; Ishikura, T; Ozaki, A. A improvement of kasugamycin: producing strain by the agar piece method and prototroph method. Folia Microbiol., v. 16, n. 3, p. 218-224, 1971.

Madigan, M. T.; Martinko, J. M.; Dunlap, P. V.; Clark, D. P. Microbiologia de Brock. Porto Alegre: Artmed, 2010.

Marschner, P.; Crowley, D.; Yang, C. H. Development of specific rhizosphere bacterial communities in relation to plant species, nutrition and soil type. Plant Soil, v. 261, n. 1/2, p. 199-208, 2004. http://dx.doi.org/10.1023/B:PLSO.0000035569. 80747.c5

Mendes, T. D. Atividade antimicrobiana de actinobactérias isoladas de formigas Atinni (Hymenoptera: Formicidae). Rio Claro: Universidade Estadual Paulista "Júlio de Mesquita Filho”, 2010. (Dissertação de Mestrado).

Senthil-Rajan, D.; Rajkumar, M.; Srinivasan, R.; Kumarappan, C.; Arunkumar, K.; Senthilkumar, K. L.; Srikanth, M. V. Investigation on antimicrobial activity of root extracts of Thespesia populnea Linn. Trop. Biomed., v. 30, n. 4, p. 570-578, 2013. Disponível em: <http://www.msptm.org/files/ 570_-_578_Dharmalingam_SR.pdf $>$. Acesso em: 01 de abril de 2016.
Silva-Lacerda, G. R.; Santana, R. C. F.; VicalviCosta, M. C. V.; Solidônio, E. G.; Sena, K. X. F. R.; Lima, G. M. S.; Araújo, J. M. Antimicrobial potential of actinobacteria isolated from the rhizosphere of the Caatinga Biome plant Caesalpinia pyramidalis Tul. Genet. Mol. Res., v. 15, n. 1, p. 1-12, 2016. http://dx.doi.org/10.4238/gmr.15017488

Takahashi, J. A.; Lucas, E. M. F. Ocorrência e diversidade estrutural de metabólitos fúngicos com atividade antibiótica. Quím. Nova, v. 31, n. 7, p. 1807-1813, 2008. http://dx.doi.org/10.1590/S010040422008000700036

Zhao, X. Q.; Jiao, W. C.; Jiang, B.; Yuan, W. J.; Yang, T. H.; Hao, S. Screening and identification of actinobacteria from marine sediments: investigation of potential producers for antimicrobial agents and type I polyketides. World J. Microb. Biot., v. 25, n. 5, p. 859-866, 2009. http://dx.doi.org/10.1007/s11274-0099964-y 